Received: November 15, 2017

\title{
Research on the Impact of Internet Development on the Quality of China's Higher Education
}

\author{
Qiang Chen ${ }^{1}$ \\ Hunan University
}

\author{
Yi Fan ${ }^{2}$ \\ Central south university of Forestry and Technology
}

\begin{abstract}
With the development of network information in China, the application scope of "Internet + " is more and more extensive. For China's higher education, the Internet is also playing a significant role. From the network literature to the current network teaching, the Internet has affected the way of college students to receive education in various ways. Therefore, with the development of network, does the Internet exert a significant impact on the quality of China' higher education? This paper conducts an empirical analysis of the impact of Internet development on the quality of China's higher education from 31 provincial-level data from 2010 to 2016. The research results show that the Internet development has a significant role in promoting the quality of higher education. In the regional analysis, it is found that the Internet effect in central and western regions is higher than that in eastern regions. The regional differences show that the Internet is more effective in improving the quality of higher education in economic backward areas and narrowing the regional differences of education level.
\end{abstract}

\section{Keywords}

Internet • Quality of Higher Education • Regional Difference

\footnotetext{
${ }^{1}$ The School of Economics and Trade, Hunan University, 410082, China. Email: paperway@ sina.cn

${ }^{2}$ Correspondence to: Central South University of Forestry and Technology, 410004, China. Email: fanyi1231@126.com
} 
Higher education is the core link in the talent cultivation system and the quality of higher education directly affects the development of society, economy and culture. According to statistics, the number of colleges and universities in China in 2017 exceeded 2,900 and the number of graduates in 2018 exceeded 8 million. It can be seen that the quality of higher education is directly related to the high-level human resources and talents in the country. In recent years, with the development of Internet, people's work and life styles have undergone tremendous changes, from the letter in the past to the mobile communication in present day, from traditional stores in the past to the e-commerce in present day. The Internet has affected the work and life styles of people all the time.

Similarly, the Internet has exerted an important impact on education. From one school, one teacher and one classroom in the past to one computer and one mobile phone in present day. Students can also accept knowledge from all over the world. The data shows that in the first half of 2018, the number of Chinese netizens has exceeded 800 million and the Internet penetration rate is $57.7 \%$. Among them, the number of mobile Internet users in China reaches 788 million, of which the number of mobile phone readers continues to grow, reaching 381 million, accounting for $48.3 \%$ of total mobile Internet users. The Internet has also exerted a significant impact on higher education in our country. From the online library in the beginning to the online classroom in present day, the Internet affects the college students in China all the time. The rise of network teaching modes such as MOOC has greatly reduced the learning cost for learners, enabling learners to break the geographical and time limitation and learn online courses of prestigious universities around the world. At the same time, under the development of Internet-based teaching, students have also transformed from passive learners to active learners, becoming the sharers and participants of knowledge.

The development of the Internet will promote the sharing of educational resources to the greatest extent so that the public can share high-quality educational resources; the learning resources will not be restricted by geography and time, and learners can learn knowledge in different ways such as text, images, audio and video; teachers can complete the teaching and teaching management through cloud platform, remote video interactive platform and traditional multimedia teaching equipment. At the same time, under the development of the Internet, a new mobile classroom mode has emerged under the development of Internet. The mobile classroom is a new classroom teaching method based on mobile network platform, which has been welcomed by more and more teachers and students. The advantage of this mode is that it can effectively enable teachers or students to share videos, record their teaching and learning and share with each other without the limitation of time and space. The functions of mobile classroom include live courses, course recording and spreading online courses on the Internet. With the advent of various wireless products and the application of various teaching software, the convenient "flipped classroom teaching" is increasingly welcomed by teachers and students. In the future, students will have the freedom to choose and even customize the time, place and mode of college. Learners will no longer be influenced by time and space but to learn at anytime, anywhere. Nowadays, although online teaching has presented many new ways and its convenience, it is still in the development stage and it takes a long time to replace traditional higher education. With the development of Internet, colleges and universities have paid more and more attention to the construction of Internet infrastructure. The construction of digital campus has gradually been emphasized. The mode of digital campus construction in many universities has also transformed from independent construction to joint construction of schools and enterprises. The idea of the 
construction has gradually transformed from digital campus to intelligent campus. In the construction of digital campus, many colleges and universities pay special attention to the construction of wireless campus network. The wireless network is characterized by flexible deployment, high bandwidth and flexible access, which enables users to have more flexible access to various teaching and research resources. With the further development of wireless technology, it will lead the education information into a new world.

In the research field, the influence of Internet on China's higher education has also received much attention from many scholars. (Zhang 2013; Pan and Liao, 2014; Li and Li, 2017; Shang and Cao, 2017; Wen, 2017) The impact of Internet on higher education is both a challenge and an opportunity. Many scholars hold their own views on the impact of Internet on higher education. Sang Lei (2016) believed that the evolution and reform of the teaching community under the background of "Internet +" has changed the traditional teaching field to a certain extent. The teaching activities have gradually extended from "physical space" to "virtual space", which overthrew the relative closed "teaching wall" of the school. The deadlock between teachers and students in the traditional teaching community was broken and a multi-line bond between teachers and students was established. The function and position of teachers and students was repositioned in the new teaching field. As for the impact of Internet on higher education, there is a view that the Internet will replace the role of teachers and the traditional college teaching system will face a huge impact. Liu (2017) believed that this view exaggerated the challenge faced by colleges and universities in the era of "Internet + " and ignored the opportunities. In fact, while the Internet has brought about changes in teaching scenes, teacher-student relationship and teaching process, the original teaching essence and logic of higher education have not changed, but have been further strengthened. Hoxby (2014) found that although MOOC offered many higher education courses, it could enable students to communicate with teachers like in school. At the same time, MOOC would not provide many practice opportunities for students. Zhong (2015) believed that although Internet technology was making an important contribution to the development of education, it was also necessary to see that there were many problems in the Internet-based teaching mode, so it need to be constantly improved. The course teaching cannot be completely equivalent to education. The ultimate goal of education is to cultivate all-round talents. The core function of the university is to train high-level professionals with all-round development of morality, intelligence, physique and aesthetics and to provide human resources support and intellectual contribution for economic construction and social development. The law of education and talent growth should be obeyed to ensure and improve the quality of talent cultivation. The teaching and management work should be carried out around the construction of moral principles and education should be conducted by whole staff, in all aspects and through the whole process.

Although the Internet has promoted the change in teaching modes and improved the learning efficiency to some extent, it also has shortcomings for learners. Zhang (2016) believed that autonomous learning also brought some negative effects on learners. For example, the problem of fragmentation. Learners lack deep thinking for the fragmented information that is readily available. Another problem is the lack of compulsory learning. The learning in the Internet environment often pursues a fun and entertaining experience, and it is difficult for learners to have time and patience to sit down and learn the boring basic knowledge. Also, it is difficult to screen information. It is difficult for learners, especially young learners who lack the ability of judgement, to carry out effective knowledge accumulation and processing and enhance their ability without correct guidance facing the 
huge amount of information mixed with good and evil. The solution of these issues requires the intervention of new ideas and forms of education. Liu (2016) believed that with the rapid development of information technology, more and more people were caught in the virtual world of the network and college students were no exception. Smartphones and online games have become the two killers that damaged the school, physical and mental health of college students. Irregular diet, sleep and exercise insufficiency are the main factors leading to the decline in the physical function and physical fitness of college students with Internet addiction.

Although there are some problems with the Internet, the benefits of Internet for higher education is greater than its shortcomings. Based on this, this paper will study the impact of Internet development on China's higher education. This paper thinks that the impact of Internet development on the quality of higher education is reflected in two aspects: (1) The development of Internet reduced the time of learners to search for learning information. Also, it breaks the geographical restriction, thereby reducing the cost of information gathering for learners and greatly enhancing the learning efficiency of learners. (2) The Internet will enhance the scope of teachers' influence in teaching and expand the spillover effect of high-quality teaching resources. At the same time, the Internet can store teaching materials on the Internet for a long time, improve the frequency of use of teaching resources and reduce the time cost of teaching, thereby achieving the goal of improving teaching efficiency. The empirical analysis is used in this paper to analyze the impact of Internet development on higher education. The main contributions of this paper are: First, the empirical analysis method is used to study the impact of Internet development on the quality of higher education in China. Second, it considers the regional differences in China and study the regional differences in the impact of Internet development on the quality of higher education in China.

\section{Research Method}

\section{Model Introduction}

In the empirical analysis, the quantitative analysis method will be used in this paper to analyze the impact of Internet development on the quality of higher education in China. In quantitative analysis, OLS (Ordinary Least Square) (Zhang, 2016) is a common and classic model, (Hong and Kacperczyk, 2010) which is widely used in quantitative empirical study. Therefore, the OLS model is used in this paper to analyze the impact of Internet development on the quality of higher education. The measurement model selected in this paper is as follows:

$$
Y_{i t}=+{ }_{1} N E T_{i t}+{ }_{2} E C O_{i t}+{ }_{3} E D L_{i t}+{ }_{4} \mathrm{OPEN}_{i t}+{ }_{5} \mathrm{TIN}_{i t}+{ }_{i}+{ }_{t}+{ }_{i t}
$$

$Y$ represents the quality variable of higher education; NET represents the Internet variable (where NET is measured by NET1 and NET2). The control variables include: economic development level variable (ECO), educational foundation level variable (EDL), openness variable (OPEN), and transportation variable (TIN). Since it is panel data, this paper uses time fixed $\left(\varepsilon_{t}\right)$ and regional fixed effect $\left(\varepsilon_{i}\right) \cdot \varepsilon_{i t}$ indicates a random disturbance term. 
In addition, the development speed of the Internet is faster than the quality improvement of colleges and universities and the application of the Internet in college education is mainly guided and promoted by the government. The endogeneity between them is relatively weak. Therefore, this paper only considers the impact of the rapid development of the Internet as an external variable on the quality of college education.

\section{Data Declaration}

The data in this paper is from the panel data of 31 provincial regions in China from 2010 to 2016. The main data source is China Statistical Yearbook, China Financial Yearbook, China Education Yearbook and the National Bureau of Statistics. The explanatory variable in this paper is the quality of higher education (indicated by EDQ) and this variable is represented by the ratio of the number of graduates who get the degree certificate and the number of graduates (completion) in colleges and universities. The main explanatory variables are the Internet indexes (indicated by NET), which is measured by the mean of Internet penetration rate and mobile phone penetration rate. At the same time, this paper selects the Internet penetration rate index (indicated by NET2) and the mobile phone penetration rate index (indicated by NET3) as the index of robustness test. The following control variables that affect the quality of higher education are added in this paper: (1) Economic development level (indicated by ECO). This paper selects GDP per capita as the index of economic development level. (2) Education foundation level (indicated by EDL), which is represented by the proportion of fiscal expenditure on education in the GDP in this paper. (3) Openness level (indicated by OPEN), which is represented by the proportion of imports and exports of foreign-invested enterprises in the GDP. Transportation level (indicated by TIN), which is represented by the road area per capita. Table 1 is a statistical description of the variables selected in this paper, which is as follows:

Table 1

Statistical Description of Variables

\begin{tabular}{lccccc}
\hline Variable & $\mathrm{N}$ & Mean & SD & Min & Max \\
\hline EDQ & 217 & 0.495 & 0.086 & 0.281 & 0.758 \\
\hline NET & 217 & 66.122 & 18.292 & 30.535 & 132.380 \\
\hline NET2 & 217 & 45.282 & 13.087 & 19.800 & 77.800 \\
\hline NET3 & 217 & 86.961 & 24.359 & 40.870 & 189.460 \\
\hline ECO & 217 & 4.631 & 2.231 & 1.312 & 11.820 \\
\hline EDL & 217 & 0.042 & 0.023 & 0.020 & 0.163 \\
\hline OPEN & 217 & 0.136 & 0.208 & 0.00001 & 1.066 \\
\hline TIN & 217 & 14.659 & 4.466 & 4.040 & 25.820 \\
\hline
\end{tabular}

\section{Empirical Results}

First of all, this paper makes a brief description of China's development speed in recent years. As shown in Figure 1, from 2010 to 2016, the development speed of Internet in China has maintained an upward trend. In 2016, the mean value of the indexes of China's Internet development level exceeded 75, an increase of $45 \%$ compared with 2016. Figure 2 gives a brief description of the quality development of higher education in China. It can be seen from the Figure that in recent years, the quality of China's higher education has been greatly improved. In 2016, the quality of higher education in China exceeded 53\%, an increase of $23 \%$ compared with 
2010. Therefore, the Internet development and the quality of higher education in China have witnessed significant improvement. Then, this paper will further analyze whether the development of Internet has a significant role in promoting the quality of higher education in China.

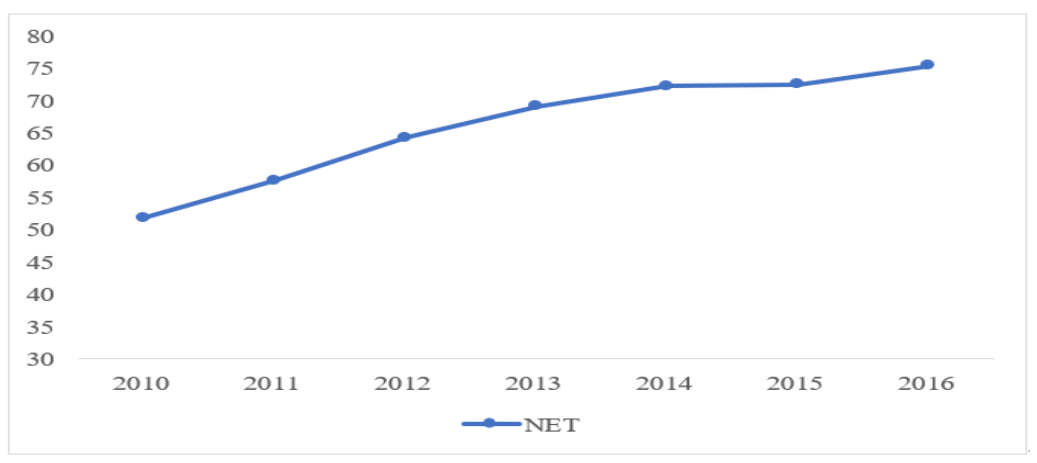

Figure 1. Internet development level in China from 2010 to 2016

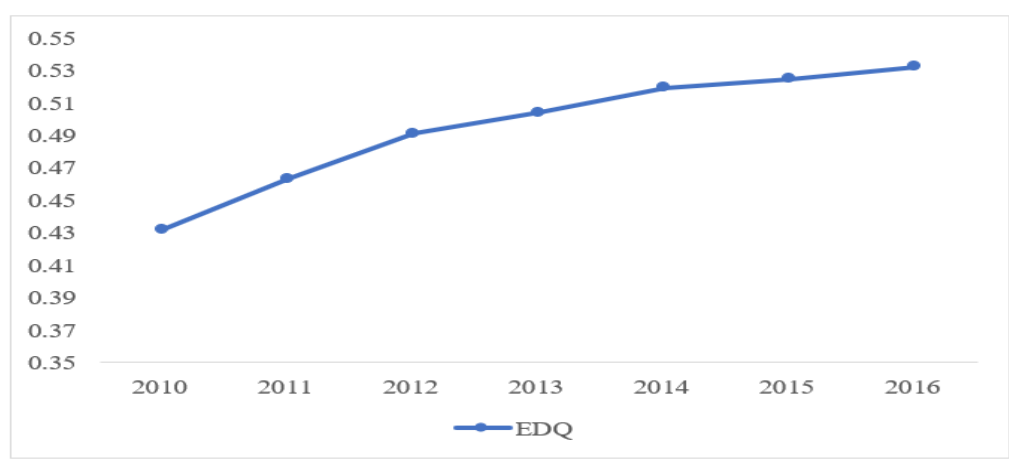

Figure 2. Higher education qualities in China from 2010 to 2016

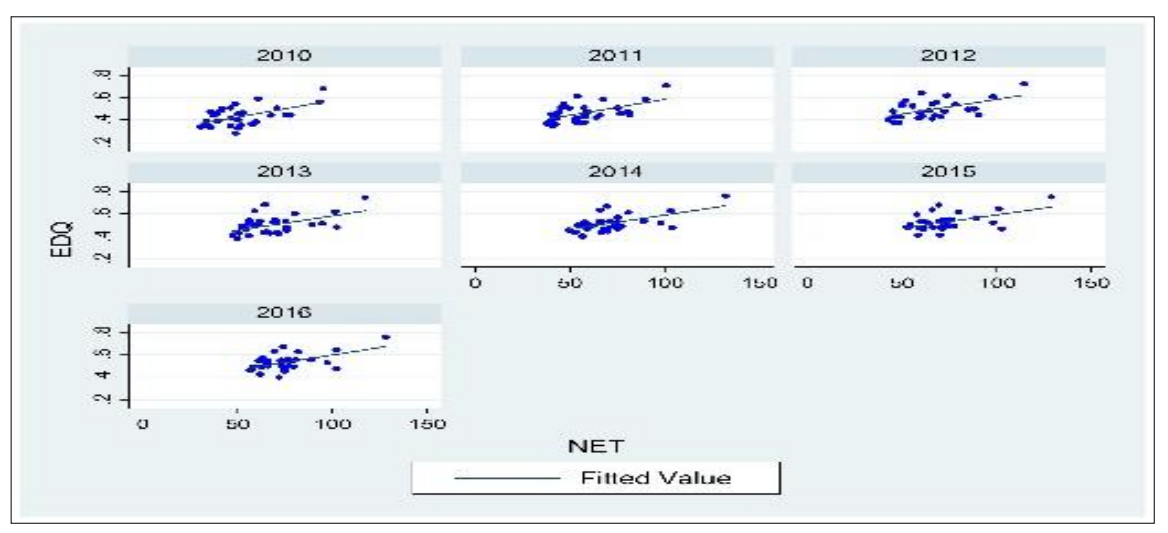

Figure 3. Scatter plot of Internet development indexes and higher education indexes 
In order to intuitively analyze the impact of Internet development on the quality of China's higher education, this paper draws a scatter plot of Internet development and the quality of higher education in China (Figure 3). It can be clearly seen from the Figure that there is a significant positive relationship between the quality of higher education and the development of Internet. In the next step, this paper will use the measurement method to analyze the impact of Internet on the quality of higher education in China.

In the measurement empirical study, first of all, this paper uses a single variable for analysis. In order to obtain more robust results, two indexes, NET2 and NET3, are used simultaneously in this paper for the analysis. In the model selection, the results of Hausman test show that all three variables suggest the selection of a random effect model. The regression results show that there is a significant positive relationship between Internet development (NET) index and higher education index. In the robustness test, the regression results of the two indexes (NET2 and NET3) selected in this paper also show that there is a significant positive relationship between Internet development and higher education. Finally, the control variables are added in this paper for analysis. Among them, the results of Hausman test suggest the selection of a fixed effect model for analysis. This result is consistent with previous analysis that there is a significant positive relationship between Internet development and higher education. This result is consistent with the view of this paper that the development of Internet can significantly improve the quality of higher education. In the regression result of control variables, it can be found that the regional economic level is also an important factor affecting the higher education index.

Table 2

Overall Empirical Analysis Results

\begin{tabular}{|c|c|c|c|c|}
\hline 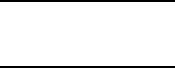 & $\begin{array}{l}\text { OLS Model } \\
\text { (Random) }\end{array}$ & $\begin{array}{l}\text { OLS Model } \\
\text { (Random) }\end{array}$ & $\begin{array}{l}\text { OLS Model } \\
\text { (Random) }\end{array}$ & $\begin{array}{l}\text { OLS Model } \\
\text { (Fix) }\end{array}$ \\
\hline NET & $\begin{array}{c}0.0038^{* * *} * \\
(0.0003)\end{array}$ & & & $\begin{array}{c}0.0030 \text { *** } \\
(0.0007)\end{array}$ \\
\hline Net 2 & & $\begin{array}{c}0.0052^{* * *} * \\
(0.0004)\end{array}$ & & \\
\hline Net 3 & & & $\begin{array}{c}0.0027 * * * * \\
(0.0003)\end{array}$ & \\
\hline ECO & & & & $\begin{array}{l}0.0141^{*} \\
(0.0082)\end{array}$ \\
\hline EDL & & & & $\begin{array}{c}-0.1484 \\
(0.5529) \\
\end{array}$ \\
\hline OPEN & & & & $\begin{array}{c}0.0928 \\
(0.1012)\end{array}$ \\
\hline TIN & & & & $\begin{array}{c}-0.0009 \\
(0.0017) \\
\end{array}$ \\
\hline Constant & $\begin{array}{c}0.2438^{* * * *} \\
(0.0255)\end{array}$ & $\begin{array}{c}0.2611 * * * * \\
(0.0225)\end{array}$ & $\begin{array}{c}0.2644 * * * * \\
(0.0292)\end{array}$ & $\begin{array}{c}0.2367 * * * \\
(0.0320)\end{array}$ \\
\hline $\mathrm{R}$-square & 0.3880 & 0.3280 & 0.3942 & 0.3375 \\
\hline Hausman-test & 2.73 & 3.26 & 1.32 & $18.84 * * *$ \\
\hline
\end{tabular}

Note. ${ }^{* * *}, * *$, and $*$ indicate the significance level of $1 \%, 5 \%$, and $10 \%$ respectively, and what within brackets is the standard error.

In order to further consider the regional heterogeneity of Internet for the quality of education, this paper divides the sample into the eastern, western and central regions respectively. From the regional analysis results, the regression results show that there is a significant positive relationship between Internet development and the quality of higher education in China in these three regions. However, the regional regression results show obvious differences. The Internet effect in the central and western regions is significantly higher than that in the 
eastern region. It shows that the role of Internet development for the improvement of the quality of higher education is more prominent in the central and western regions of China, which is related to the fact that the economy in the eastern region is more developed (Peng, 2015) and the economy in the central and western regions is relatively backward. Due to the backwardness of the economy, the infrastructure is still incomplete, so students have relatively limited access to educational resources. Therefore, the promotion role of Internet in the central and western regions is much more significant than that in the eastern region.

Table 3

Empirical Analysis Results of Different Regions

\begin{tabular}{|c|c|c|c|}
\hline & $\begin{array}{c}\text { OLS Model } \\
\text { (Eastern Region) } \\
\text { (Fix) }\end{array}$ & $\begin{array}{c}\text { OLS Model } \\
\text { (Central Region) } \\
\text { (Random) } \\
\end{array}$ & $\begin{array}{c}\text { OLS Model } \\
\text { (Western Region) } \\
\text { (Random) }\end{array}$ \\
\hline NET & $\begin{array}{l}0.0018^{*} \\
(0.0009) \\
\end{array}$ & $\begin{array}{c}0.0033 * * * \\
(0.0005) \\
\end{array}$ & $\begin{array}{c}0.0040 * * * \\
(0.0013) \\
\end{array}$ \\
\hline $\mathrm{ECO}$ & $\begin{array}{c}0.0134 \\
(0.0078) \\
\end{array}$ & $\begin{array}{c}0.0318^{* * * *} \\
(0.0035) \\
\end{array}$ & $\begin{array}{l}-0.0065 \\
(0.0101) \\
\end{array}$ \\
\hline EDL & $\begin{array}{l}2.6390 * \\
(1.4026) \\
\end{array}$ & $\begin{array}{c}0.3185 \\
(0.7702) \\
\end{array}$ & $\begin{array}{l}-0.0963 \\
(0.3570) \\
\end{array}$ \\
\hline OPEN & $\begin{array}{c}0.0523 \\
(0.0951) \\
\end{array}$ & $\begin{array}{c}0.1991 \\
(0.1897) \\
\end{array}$ & $\begin{array}{c}0.0066 \\
(0.1533) \\
\end{array}$ \\
\hline TIN & $\begin{array}{l}-0.0010 \\
(0.0026) \\
\end{array}$ & $\begin{array}{l}-0.0014 \\
(0.0041) \\
\end{array}$ & $\begin{array}{l}-0.0014 \\
(0.0019) \\
\end{array}$ \\
\hline Constant & $\begin{array}{c}0.2024 * * * \\
(0.0498)\end{array}$ & $\begin{array}{c}0.1864 * * * \\
(0.0584)\end{array}$ & $\begin{array}{c}0.2907 * * * \\
(0.0371)\end{array}$ \\
\hline R-square & 0.5969 & 0.5447 & 0.2071 \\
\hline Hausman-test & $12.17 * *$ & 1.50 & 5.59 \\
\hline
\end{tabular}

Note: ***,**, and * indicate the significance level of $1 \%, 5 \%$, and $10 \%$ respectively, and what within brackets is the standard error.

\section{Conclusion}

Based on the provincial panel data of 31 provinces from 2010 to 2016, this paper analyzes the impact of Internet development on the quality of higher education in China. Through the study of this paper, the following findings are obtained: (1) In recent years, the development of Internet in China has exerted significantly positive impact on the quality of higher education in China. (2) Internet development has a significant positive impact on the quality of higher education in China. (3) There are significant regional differences in the impact of Internet on the quality of higher education in China. Among them, the Internet effect in the western region is the most significant. Meanwhile, the Internet effect in the central and western regions is significantly higher than that in the eastern region. Finally, this paper believes that with the development of Internet, it will inevitably have a greater impact on higher education, but this impact may be mainly concentrated in the teaching form, educational resources and the reduction of teaching costs. Under the development of Internet, people's demand for knowledge will be greatly enhanced, which will promote the increase in the demand for teachers, thus further enriching the resources of higher education. Therefore, the development of Internet not only enriches the resources of higher education in China, but also improves the quality of higher education. The specific path and mechanism of the impact of Internet on the quality of higher education call for further researches. 


\section{References}

Gordon, B. (2012). Dahl, Lance Lochner. The Impact of Family Income on Child Achievement: Evidence from the Earned Income Tax Credit. The American Economic Review, 102(5), 1927-1956 http://dx.doi.org/10.1257/aer.102.5.1927

Hong, H., \& Kacperczyk, M. (2010). Competition and Bias, Quarterly Journal of Economics. 125(4), 16831725. http://dx.doi.org/10.1162/qjec.2010.125.4.1683

Hoxby, C. M. (2014). The Economics of Online Postsecondary Education: Moocs, Nonselective Education, and Highly Selective Education, American Economic Review, 104(5), 528-533. http://dx.doi.org/10.1257/aer.104.5.528

Li, P. P., \& Li, X. S. (2017). New Way on Cultivating College Students' Collaborative Innovation Ability Under the Information Environment. Research in Higher Education of Engineering, (2), 199-202.

Liu, F. M. (2014). Effect of Internet Addiction on College Students' Physical Fitness and Its Intervention Strategies: Taking the Universities in Guangdong Province as Examples. Journal of Beijing Sport Wooldridge, JeffreyM. Introductory econometrics / 4th ed, Higher Education Press.

Liu, G., Li, J., \& Liang, H. (2017). University Teaching Innovation in the "Internet+" Era: Consideration and Countermeasures. China Higher Education Research, (2), 93-98.

Pan, Y. T., \& Liao, Y. Y. (2014). The MOOC Trends of Information Literacy Education for Undergraduate Students. Journal of Academic Libraries, 32(4), 21-27.

Peng, G. H. (2015). The Matching of skills to tasks, labor migration and Chinese regional income disparity. Economic Research Journal, (1), 99-110

Sang, L. (2016). The evolution and reconstruction of teaching community under the background of "Internet +". Higher Education Exploration, (3), 79-82.

Shang, J. J., \& Cao, P. J. (2017). The Preliminary exploration of development strategy of higher education informatization in China. Peking University Education Review, 15(1), 173-182.

Wen, J. (2017). International development of education from the perspective of "Internet +". China Higher Education, (5), 22-24.

Zhang, S. G. (2013). MOOCs: The Collision between the Concept of Web-based Education and Educational Management System, China Higher Education Research, (12), 16-19.

Zhang, Y. (2016). On the concept and mode of "Internet Plus Education". China Higher Education Research, (2), 70-73.

Zhang, Y. B., Chen, Q., Yuan, R. Q. (2017). The Study of factors misallocation and carbon emission efficiency under the background of supply side reform in China. Academic Research, (5), 79-85.

Zhong, B. L. (2015). Internet Teaching and Talents Training in University. China University Teaching, (9). 